\title{
Problemas de Aritmética: participação na marcha de ensino e na relação com a vida prática (cadernos de alunos franceses -1890 a 1936)
}

\author{
Arithmetic Problems: participation in the teaching march and in the \\ relation with students' practical lives (French students' notebooks - 1890 to
}

1936)

Luciane de Fatima Bertini*

ORCID iD 0000-0003-0948-4745

\begin{abstract}
Resumo
O presente texto tem como objetivo principal discutir como as propostas para a utilização de problemas no ensino de Aritmética estiveram presentes nas salas de aula do Ensino Primário, tendo como corpus 72 cadernos franceses do período entre 1870 e 1936. Tal discussão envolveu, além da exploração dos cadernos, as relações com as prescrições e as orientações para o ensino de Matemática na Escola Primária francesa nesse período histórico. A análise teve como referenciais o conceito de consumo de Certeau, a perspectiva dos cadernos como produto e produtor da cultura escolar, segundo Gvirtz e Larrondo, e a importância de considerar a existência de regras específicas para o uso dos cadernos, mencionada por Viñao. Os resultados apontam que, ao longo do tempo, as temáticas envolvidas nos problemas, aos poucos deixam de abordar aspectos da vida no campo e a marcha do ensino, que inicialmente envolvia problemas de um único tipo (proporcionalidade), entre $1915 \mathrm{e}$ 1936, passa a envolver a centralidade de determinado conteúdo - relacionado também a problemas-tipo - e a propor uma sequência de conteúdos. Além disso, considera-se que nesse momento histórico os problemas estavam presentes nos cadernos escolares como um saber a ser ensinado.
\end{abstract}

Palavras-chave: Problemas. Ensino de Aritmética. Ensino Primário. Cadernos Escolares. Saber.

\begin{abstract}
This article discusses how proposals for the use of problems in arithmetic teaching were present in primary school classrooms. The corpus consists of 72 French notebooks from the period between 1870 and 1936. Besides the notebooks' exploration, the discussions approached the relations with prescriptions and guidelines for mathematics teaching in French primary school in that historical period. The theoretical framework for the analysis involved Certeau's consumption concept, Gvirtz and Larrondo's perspective of the notebook as both a product and a producer of school culture, and the importance of considering the existence of specific rules for the use of notebooks, as mentioned by Viñao. The results show that, over time the themes used in problems little by little stopped approaching aspects of life in the countryside, and the teaching march, which initially involved only one type of problem (proportionality), started to approach the centrality of a specific content - also related to type-problems - and to propose a sequence of contents in the period between 1915 and 1936. In addition, we take into consideration the fact that, in that historical period, problems were present in notebooks as some knowledge to be taught.
\end{abstract}

\footnotetext{
* Doutora em Educação, Universidade Federal de São Carlos (UFScar). Professora adjunta, Universidade Federal de São Paulo (UNIFESP), Diadema, SP, Brasil. Endereço para correspondência: Rua Visconde de Inhaúma, 178, apartamento 606, Saúde, São Paulo, SP, Brasil, CEP: 04145-030. E-mail: lfbertini@ gmail.com.
} 
Keywords: Problems. Mathematics Teaching. Primary School. School Notebooks.

\section{Résumé}

L'objectif principal de ce texte est de discuter comment les propositions d'utilisation des problèmes d'enseignement de l'arithmétique étaient présentes dans les salles de classe de l'école primaire, ayant pour corpus 72 cahiers français datant de la période comprise entre 1870 et 1936. La discussion a impliqué l'exploration des cahiers et les relations avec les prescriptions et les orientations pour l'enseignement des mathématiques à l'école primaire française de cette période historique. L'analyse avait pour référence le concept de consommation de Certeau, la perspective des cahiers en tant que produit et producteur de la culture scolaire, selon Gvirtz et Larrondo, et l'importance de considérer l'existence de règles spécifiques pour l'utilisation des cahiers, mentionnées par Viñao. Les résultats montrent que, au cours du temps, les thématiques des problèmes sont progressivement moins liés aux aspects de la vie rurale et que la démarche de l'enseignement, qui comportaient initialement des problèmes de type unique (proportionnalité), entre 1915 et 1936 commence à impliquer la centralité de certains contenus - également liés à des problèmes-type - et à proposer une séquence de contenus. De plus, on considère que, dans ce moment historique, les problèmes étaient présents dans les cahiers scolaires en tant que savoir à enseigner.

Mots-clés : Problèmes. Enseignement de l'Arithmétique. École Primaire. Cahiers Scolaires. Savoir.

\section{Introdução}

A temática da utilização de problemas para o ensino de Aritmética tem sido explorada por alguns estudos nacionais e internacionais (BERTINI, 2016; BURIGO, SANTOS, 2015; D’ENFERT, 2006，2015; SARRAZY，2003; SOUZA，2017; SOUZA，BERTINI，2016; VIRGENS, LEME DA SILVA, 2014), cujos resultados apontam para a existência de diferentes entendimentos do termo "problema", diferentes orientações para o seu uso para o ensino de Aritmética, diferentes finalidades para essa utilização, diferentes relações com os conteúdos matemáticos e diferentes participações na marcha de ensino. Diferenças que são observadas tanto no decorrer do tempo, como nos diferentes documentos analisados. Interessa a esses estudos, e também ao que agora se apresenta, a construção de narrativas históricas sobre como se dá esse processo de utilização dos problemas para o ensino de Aritmética, considerando as perspectivas que se mantêm ou se modificam ao longo do tempo.

Os estudos citados fizeram/fazem uso de programas, leis, manuais escolares e revistas pedagógicas, documentos nos quais estão explicitadas determinações e orientações para o ensino, seja em forma de prescrições feitas pelo poder público ou pela divulgação de modelos e propostas de ensino contidos nos manuais e nos artigos das revistas. Mas, como se dá o consumo de determinações e orientações? Como as propostas para a utilização de problemas no ensino de Aritmética têm estado presentes nas salas de aula do ensino primário? Os cadernos escolares se apresentam como uma possibilidade para a busca de respostas a essas perguntas. 
Tais questões guiaram a pesquisa ${ }^{1}$ aqui apresentada, que tomou como documentos de análise cadernos de alunos franceses no período entre 1870 e 1936, e como consequência, envolveu a exploração das determinações e propostas para o ensino francês, e mais especificamente para o ensino de Matemática nesse período histórico.

Na primeira questão apresentada, o uso do termo consumo é utilizado na perspectiva de Certeau. Para este autor, a relação de consumo se dá nas "maneiras de empregar os produtos impostos" (CERTEAU, 2014, p. 39, grifos do autor), em um processo criativo e plural. Entre aqueles reconhecidos como produtores, o autor identifica as instituições oficiais e também autores, pedagogos, revolucionários. Assim, neste estudo, o conceito de consumo envolve as maneiras de fazer na escola em relação às determinações (leis, programas de ensino) e às orientações para o ensino (presentes em alguns documentos oficiais e também nos manuais escolares em circulação).

\section{Os problemas nas determinações e orientações para o ensino}

No período da Terceira República, interesse principal da pesquisa apresentada neste texto, D’Enfert (2006) identifica que a escola francesa vive uma dualidade: a escola primária elementar (até 12 anos) se apresenta como a "escola do povo" e prepara para a vida; e, de outro lado, a escola secundária revela-se a "escola dos notáveis", por meio de um ensino teórico. E, em relação ao ensino de Matemática, esse pesquisador divide o período em dois momentos: o primeiro é denominado por ele de "L'école républicaine: le renouvellement pédagogique $^{2}$ (1870-1914)” (D’ENFERT, 2003); e o segundo, “Un enseignement mathématique entre tradition et novation ${ }^{3}$ (1915-1936)" (D’ENFERT, 2015). Para D’Enfert (2003), a década de 1870 representa um movimento de renovação ideológica. O autor afirma que a educação científica advogada pelos republicanos repousa sobre os métodos pedagógicos, sendo o método intuitivo uma recomendação.

Ainda, em relação a este período histórico (1870 a 1914), Sarrazy (2003) identifica que, por meio da Lei orgânica de 30 de outubro de 1886 e do Decreto de 18 de janeiro de 1887, o problema de Aritmética ganhou lugar no ensino e o ensino de Aritmética deixou de ficar limitado apenas à contagem, às quatro operações e à regra de três.

\footnotetext{
${ }^{1} \mathrm{O}$ texto aqui apresentado foi constituído a partir de uma pesquisa de pós-doutorado realizada na Université de Limoges, no ano de 2017, com financiamento CAPES-COFECUB, e de um projeto de pesquisa com financiamento do $\mathrm{CNPq}$, ainda em desenvolvimento.

${ }^{2}$ Escola republicana: renovação pedagógica

${ }^{3}$ Um ensino de matemática entre tradição e inovação
} 
Nessas documentações, o autor destaca a orientação de que o ensino de Aritmética deve envolver o ensino de regras que permitam a resolução de "problemas-tipo", levando, segundo Sarrazy (2003), a desconsiderar a capacidade de conceitualização das crianças, por ser baseada no "adestramento", na memorização e na repetição. Tal proposta envolveria conhecimentos necessários para a vida social (relacionados a temáticas como: comércio, indústria, agricultura, gestão doméstica), bem como a formação de valores morais.

Ao apresentar as propostas em vigência entre 1915 e 1936, D’Enfert (2015) diferencia esse período do anterior por meio de dois aspectos principais: a forma de participação dos alunos no processo de ensino, que passou a propor um ensino "pela ação" em substituição ao ensino pela observação, e a organização dos programas escolares, que substitui o ensino concêntrico por uma organização na qual cada curso e cada ano escolar apresenta um programa próprio, garantindo assim a não-monotonia e a adequação do ensino aos alunos - à sua idade e ao seu destino escolar e social.

Dessa forma, ensino primário, secundário e técnico apresentam diferentes finalidades: o ensino primário prepara para a vida, incluindo a preparação do cidadão e também do futuro trabalhador; a proposta é de um ensino utilitário e ao mesmo tempo educativo (D'ENFERT, 2015).

No ensino de Matemática, de acordo com D’Enfert (2015), tais finalidades se refletem em propostas de ensino que envolvem a realização dos cálculos com rapidez e exatidão e a resolução de problemas com os quais os estudantes podem se deparar na vida cotidiana (ainda que futura). Um exemplo é o destaque dado para o caráter prático presente no Programa de 1923: nas instruções que o acompanham há uma indicação sobre a necessária conscientização de que a maioria das crianças irá ganhar a vida por meio do trabalho e que, por isso, devem ser munidas de conhecimentos práticos que possam servir à sua futura profissão.

Ainda sobre o Programa de 1923, Sarrazy (2003) afirma que há uma continuidade em relação às propostas anteriores e, assim, identifica em manuais escolares dos anos 1923, 1924, o papel central ocupado pelos "problemas-tipo", que exigem das crianças a compreensão, a memorização e a reprodução das "soluções-tipo". Apesar de apontar algumas mudanças nas propostas desses manuais, como a utilização de ilustrações e de temáticas da atualidade (esportes, descobertas do momento), Sarrazy (2003) conclui não haver mudanças em relação ao esquema didático proposto anteriormente.

A finalidade de preparar para a vida, de acordo com D'Enfert (2006), dá à resolução de “problemas usuais" um papel essencial no ensino de Matemática na escola primária (D'ENFERT, 2006, p. 73). Para o trabalho com esse tipo de problema, o autor identifica as 
orientações para que envolvam quantidades e práticas relacionadas a situações reais que possam ser encontradas na vida cotidiana. Assim, destaca críticas realizadas por inspetores à utilização de situações que não são consideradas práticas (como problemas que envolvem o tempo que uma torneira leva para encher um lago) e trabalham valores desatualizados ou distantes dos reais (como utilização de preços antigos).

No entanto, D’Enfert (2006) chama a atenção para o fato de que essa prevalência da dimensão prática não invalida completamente a dimensão educativa nas propostas para o ensino de Matemática na escola primária francesa no período da Terceira República e destaca a preocupação com a formação moral e cívica do futuro cidadão. Exemplo disso são os clássicos problemas relativos à economia, que trazem implicitamente ideias de moralismo, e o ensino de Matemática colocado a serviço de grandes causas, como campanhas sobre os malefícios do alcoolismo (D’ENFERT, 2006, p. 74). De forma ainda mais ampla, conforme o autor, o caráter educativo relacionado ao ensino de Matemática envolve ainda a "cultura do espírito" por meio do "desenvolvimento da reflexão, do espírito crítico, do senso de rigor e de exatidão" (D’ENFERT, 2006, p. 74, tradução nossa).

Em consonância com a proposição de que o ensino de Matemática desenvolva a capacidade de reflexão e a habilidade de raciocínio, surge a crítica à utilização de "problemastipo”. A crítica, diz D’Enfert (2015), se deve ao fato de que esse tipo de problema estimula apenas a reprodução de soluções e não há reflexão. E a proposta é de que o conhecimento das operações deve preceder ao uso dos problemas, para que o aluno possa propor métodos para encontrar a solução. Sarrazy (2003) identifica, da mesma forma, críticas à utilização de “problemas-tipo", justamente por não possibilitar a reflexão por parte das crianças; e também críticas à reprodução, pelos autores dos manuais didáticos, dos mesmos tipos de problemas exigidos nos exames do certificado de estudo ${ }^{4}$, ficando a cargo desses exames a determinação do conteúdo a ser ensinado e dos problemas utilizados no ensino de Aritmética. Decorre daí uma preocupação maior com a aprovação nos exames do que com o ensino de Aritmética.

Ainda, nesse período de 1915 a 1936, D’Enfert (2015) identifica algumas inovações no ensino de Aritmética, Álgebra e Geometria: o sistema métrico como apoio na aprendizagem da numeração decimal; a introdução da Álgebra no curso superior das escolas elementares e estendida aos cursos femininos; e o ensino de Geometria por meio de uma

\footnotetext{
${ }^{4}$ Instituído pela Lei de 28 de março de 1882: “Arto. 6 - Il est institué un certificat d'études primaires ; il est décerné après un examen public auquel pourront se présenter les enfants dès l'âge de onze ans." ("É instituído um certificado de estudos primários, concedido após uma exame público que pode ser realizado por crianças a partir de *11 anos").
} 
abordagem concreta, experimental e ativa, associando seu ensino ao do desenho e do trabalho manual.

Considerando as determinações e orientações aqui apresentadas, interessa investigar como os problemas estiveram presentes nos cadernos escolares, discussão que comporá os próximos itens deste texto.

\section{Os cadernos}

O corpus de cadernos franceses utilizado nesta investigação é composto por cadernos do acervo da Biblioteca Universitária da Université de Limoges ${ }^{5}$, formado a partir de doações de alunos e professores. Foram identificados 72 cadernos do ensino primário (cours élémentaire - CE, cours moyen - CM, e cours supérieur - $\mathrm{CS})^{6}$, com registros de aulas de Matemática utilizados entre 1870 e $1936^{7}$, dentre os quais cadernos de deveres mensais e cadernos de deveres diários. $\mathrm{O}$ uso desses dois tipos de cadernos - com capa padronizada e páginas com linhas em seu interior, nas quais as crianças realizavam os registros - era determinado pela legislação oficial francesa.

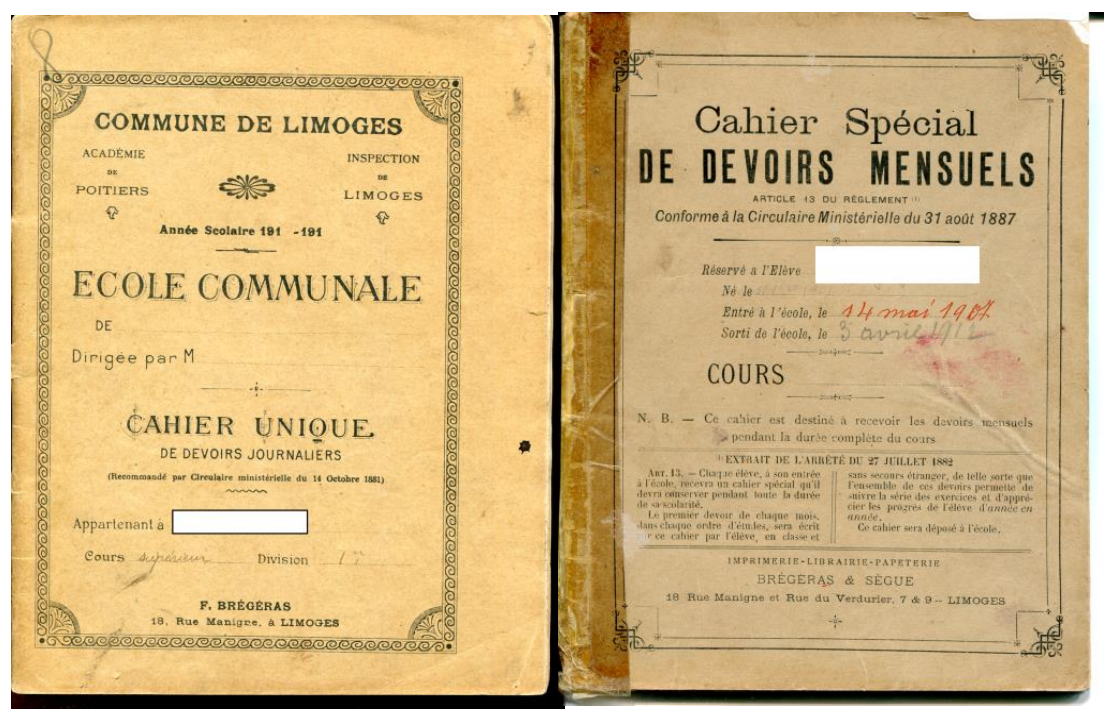

Figura 1 - Capas de cadernos de deveres diários e de deveres mensais.

Fonte: Coleção de cadernos do Fonds Histoire de l'Education da Universidade de Limoges (2017).

\footnotetext{
${ }^{5} \mathrm{O}$ acervo conta com 408 cadernos já catalogados e em fase de digitalização e disponibilização online no site: http://www.unilim.fr/histoire-education/.

${ }^{6}$ De acordo com o artigo primeiro da portaria, em relação à organização pedagógica e ao plano de estudos das escolas primárias públicas, de 27 de julho de 1882, o ensino primário nas escolas públicas francesas era dividido em três cursos: curso elementar (cours élémentaire) dos 7 aos 9 anos; curso médio (cours moyen) dos 9 aos 11 anos; curso superior (cours supérieur) dos 11 aos 13 anos.

${ }^{7}$ Tomou-se como base para seleção dos documentos a periodização apresentada por D'Enfert $(2003,2015)$ para o ensino de Matemática na legislação francesa no período da Terceira República.
} 
A determinação oficial pode ser observada nas capas dos cadernos até a década de 1920. Na Figura 1, as capas indicam a recomendação das Circulares Ministeriais de 14 de outubro de 1881 (à esquerda) e de 31 de agosto de 1887 (à direita). Ainda, na capa do caderno de dever mensal, consta um extrato do Decreto de 27 de julho de 1882 (Tradução nossa):

Art. 13. - Cada aluno, na sua entrada na escola, receberá um caderno especial que deverá conservar durante toda a sua escolaridade. O primeiro dever de cada mês, de cada matéria de estudo, será escrito pelo aluno no caderno, em classe e sem ajuda de outros, de tal forma que o conjunto dos deveres permita acompanhar a série de exercícios e apreciar o progresso do aluno de ano em ano. Esse caderno será depositado na escola ${ }^{8}$.

Foram identificadas outras capas das décadas de 1920 e 1930, também padronizadas, mas não continham a indicação oficial da Circular Ministerial. Apesar dessa exclusão nas capas, não se notou alteração em relação ao uso e à organização dos cadernos no período estudado.

Viñao (2008) faz algumas restrições em relação ao uso dos cadernos como fonte de pesquisa, pois são documentos difíceis de ser encontrados, uma vez que são pouco preservados pelas instituições e pelas famílias e não permitem acesso a tudo o que aconteceu nas salas de aula. Tais destaques alertam para as limitações deste tipo de pesquisa, mas também indicam possibilidades. Por meio dos cadernos podem-se realizar discussões a partir daquilo que foi registrado, que de alguma forma foi selecionado para compor os registros das aulas e para ser conservado.

Neste estudo, em particular, os 72 cadernos localizados não são representativos de todo o ensino francês do período analisado. No entanto, considera-se a possibilidade de sua utilização para discussões sobre o ensino de problemas nas aulas de Aritmética, principalmente pela característica do conjunto de documentos, que conta com cadernos de um mesmo aluno em diferentes anos escolares, cadernos de deveres mensais e diários de um mesmo aluno em um mesmo ano escolar, cadernos de alunos de um mesmo professor e de alunos de uma mesma classe.

A partir da análise desses cadernos, alguns aspectos puderam ser explorados, como: a organização geral dos cadernos (algumas de suas regras de uso); a marcha de ensino dos conteúdos referentes à Aritmética; a relação entre os conteúdos abordados nos problemas e em

\footnotetext{
${ }^{8}$ No original: “Art. 13. - Chaque élève, a son entrée à l'école, recevra um cahier spécial qu'ill devra conserver pendant tout ela durée de as scolarité. Le premier devoir de chaque mois, dans chaque ordre d'études, sera écrit sur ce cahier par l'élève, em classe er sans secours étranger, de telle sorte que l'esemble de ces devoirs permette de suivre la série des exercices et d'apprécier le progrès de l'élève d'année em année. Ce cahier sera dépose à l'école."
} 
outras atividades que exploram o ensino de Aritmética; a identificação de indícios de orientações dadas pelos professores de como proceder para resolver um problema; os temas que estão presentes no texto dos problemas e que buscam estabelecer a aproximação com situações da vida; e a relação entre os problemas propostos nos cadernos de deveres diários e os de deveres mensais nos quais estão registradas as avaliações.

Na continuidade deste texto, esses aspectos serão explorados, na busca de um diálogo com os programas em vigor em cada período e também com pesquisas já realizadas sobre o ensino de Aritmética no ensino primário francês, levando em conta os programas de ensino (D’ENFERT, 2006, 2015) e também a presença dos problemas nos programas e manuais escolares franceses (SARRAZY, 2003). O diálogo é estabelecido a partir da ideia de que os cadernos são, ao mesmo tempo, produtos e produtores da cultura escolar (GVIRTZ; LARRONDO, 2008) e, assim, não representam necessariamente uma simples reprodução das determinações das legislações e das indicações das vagas pedagógicas com maior representatividade nas discussões sobre o ensino em cada período.

\section{Sobre a organização dos cadernos}

De acordo com Viñao (2008), há regras específicas para o uso do caderno escolar, que precisam ser aprendidas pelas crianças. Assim, foi possível identificar, no corpus de cadernos deste estudo, algumas dessas regras: o registro pelo aluno sempre com caneta preta ou azul (com exceção das atividades de desenho, que eram feitas a lápis); a inexistência de marcas pessoais de cada aluno, apenas o registro das atividades; a presença da data de realização das atividades com dia, mês e ano; o registro do título da atividade a ser realizada (aritmética, gramática, ditado, geografia etc.); as marcas do(a) professor(a) realizadas com caneta de cor diferente, na maioria das vezes vermelha, na margem esquerda do caderno ou sobre a escrita do aluno. As marcas sobre a escrita do aluno visam corrigi-la, já as da margem esquerda se referem à avaliação do trabalho da criança, por vezes utilizando a indicação de uma nota entre zero e cinco, por vezes apresentando indicações como "bom”, “mau”, “exato", "razoável”, "medíocre".

As regras de uso do caderno são ainda observadas na organização espacial para o registro dos problemas. Mantém-se a organização já identificada por Hébrard (2001): uma primeira parte com o texto do problema; a seguir, o espaço do caderno dividido em duas colunas, nas quais se registram, na coluna à esquerda, os procedimentos de solução com frases e operações registradas na horizontal; à direita as operações na forma vertical; e ao final o 
registro da resposta.

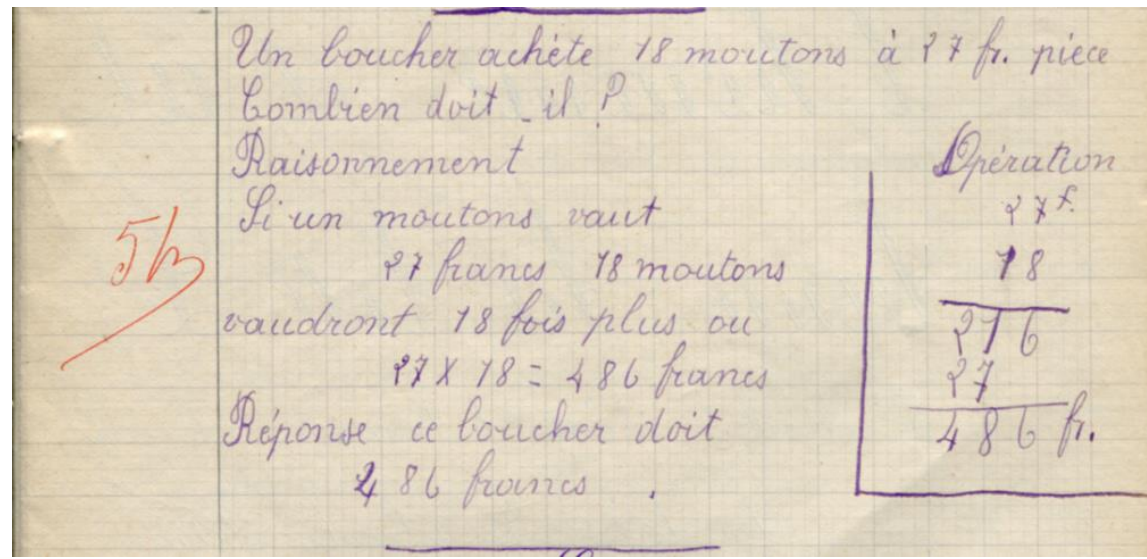

Figura 2 -Problema resolvido por João9 ${ }^{9}$, em 19 de janeiro de 1912

Fonte: Coleção de cadernos do Fonds Histoire de l'Education da Universidade de Limoges (2017).

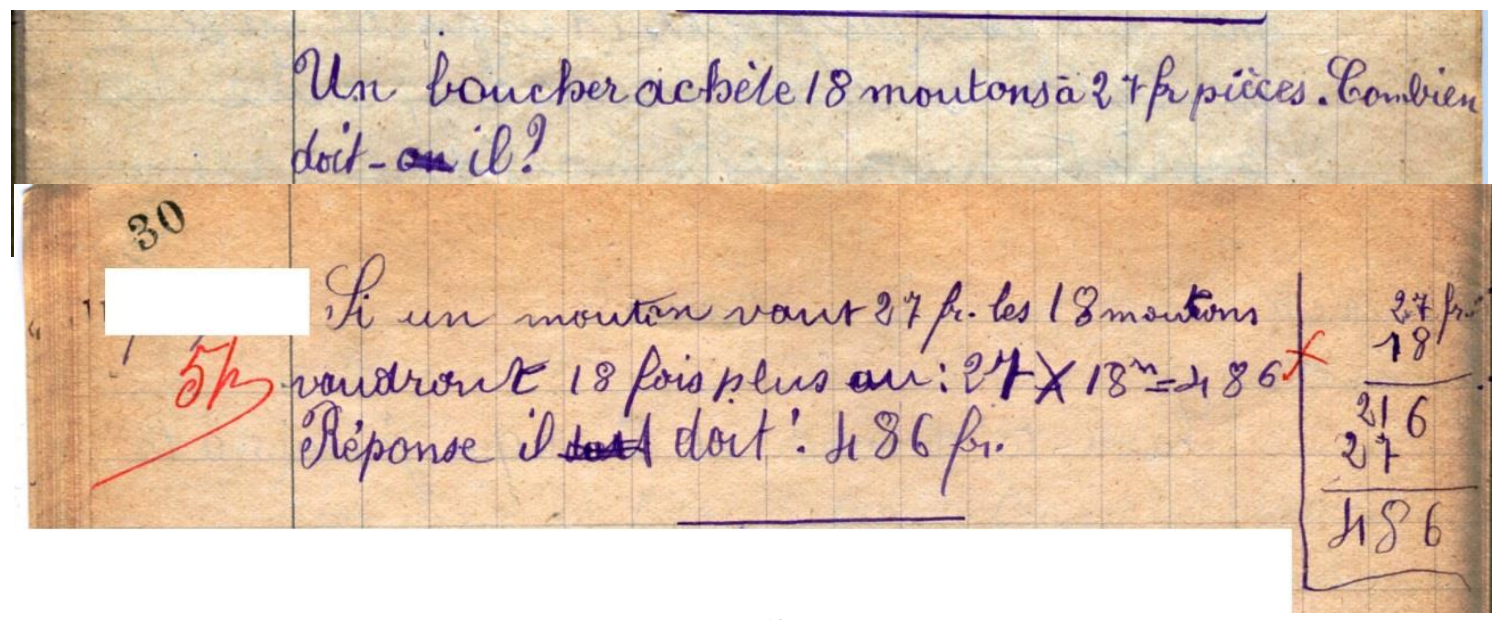

Figura 3 - Problema resolvido por Julio ${ }^{10}$ em 19 de janeiro de 1912

Fonte: Coleção de cadernos do Fonds Histoire de l'Education da Universidade de Limoges (2017).

\begin{tabular}{|l|l|}
\hline $\begin{array}{l}\text { Um açougueiro compra } 18 \text { ovelhas a } 27 \mathrm{fr} \text {. a peça. } \\
\text { Quanto ele deve? }\end{array}$ & $\begin{array}{l}\text { Um açougueiro compra } 18 \text { ovelhas a } 27 \mathrm{fr} \text {. a peça. } \\
\text { Quanto ele deve? }\end{array}$ \\
$\begin{array}{l}\text { Raciocínio } \\
\text { Se uma ovelha vale }\end{array}$ & $\begin{array}{l}\text { Se uma ovelha vale } 27 \mathrm{fr} \text {. As } 18 \text { ovelhas } \\
27 \text { francos, } 18 \text { ovelhas } \\
\text { valerão } 18 \text { vezes mais ou: } 27 \times 18 \mathrm{~m}=486\end{array}$ \\
$\begin{array}{l}\text { valerão } 18 \text { vezes mais ou } \\
27 \times 18=486 \text { francos }\end{array}$ & \\
Resposta: este açougueiro deve & Resposta ele deve: $486 \mathrm{fr}$. \\
$\quad 486$ francos. & \\
\hline
\end{tabular}

Quadro 1 - Tradução do problema das Figuras 1 e 2 respectivamente.

Fonte: Tradução livre feita pela autora (2017).

A comparação da resolução apresentada por João e por Julio (Figuras 1 e 2), alunos de uma mesma classe que resolvem um mesmo problema, revela que, para além de um modelo de organização gráfica para o registro dos problemas, havia um modelo para a escrita dos procedimentos utilizados na resolução. As frases utilizadas pelos dois estudantes para indicar

\footnotetext{
${ }^{9}$ Os nomes de alunos, neste texto, são fictícios.

${ }^{10}$ Os nomes de alunos, neste texto, são fictícios.
} 
o "Raciocínio" e a "Resposta" são muito parecidas. A mesma semelhança, que por vezes é representada por escritas idênticas, é encontrada em todos os momentos nos quais crianças da mesma sala resolvem os mesmos problemas. A existência de um modelo de resolução é, ainda, observada na resolução de problemas por uma mesma criança ao longo do tempo, ou em cadernos de alunos de diferentes professores.

$\mathrm{Na}$ correção dos problemas, algumas palavras passam a ser utilizadas nos cadernos após 1915: "justo" e "falso". A utilização destas palavras apenas para os problemas indica uma especificidade neste tipo de atividade, que parece estar relacionada a um aspecto valorizado no processo de ensino de Matemática: a exatidão. D’Enfert (2015) identifica, por exemplo, que, nas instruções para o ensino de 1923, o objetivo do ensino de Matemática está relacionado a aprender a calcular com rapidez e exatidão.

A permanência de muitas das regras e formas de uso desde 1870 até 1936 mostra que elas não são escolhas aleatórias de cada professor e que também não estão especificamente relacionadas a uma escola ou a um nível de ensino. Parecem ser representantes de um aspecto da cultura escolar que perdura, ainda que haja alterações no que é proposto nos programas de ensino e nas propostas e discussões de como deve ocorrer o ensino.

\section{Sobre a marcha do ensino}

Os problemas ocupam um lugar central nos cadernos, no que diz respeito às atividades relacionadas ao ensino de Matemática, são a atividade principal na maioria dos cadernos e dos níveis de ensino e, em alguns casos, são o único tipo de atividade registrado. Eles ganham cada vez mais espaço nos registros dos cadernos, com o passar dos anos de escolaridade. Nos cadernos do CE, por exemplo, dividem espaço com atividades como as operações, a contagem, considerando uma sequência (contar de 30 em 30, aumentando 3, multiplicando por 3 etc.) ou as relações entre múltiplos e submúltiplos das unidades de medidas. Em alguns cadernos, inclusive, nos primeiros meses do ano escolar não é proposto nenhum tipo de problema. Com o passar do tempo, os problemas passam a ser apresentados juntamente com essas atividades, e elas vão diminuindo em quantidade chegando a ser o único tipo de atividade registrada, como em alguns cadernos do CS.

Apesar dessa divisão de espaço com algumas outras atividades nos cadernos de deveres diários, nos cadernos de deveres mensais (aqueles nos quais estão registradas as avaliações mensais), essa convivência é praticamente inexistente. Os problemas são, sem dúvida, a atividade privilegiada em todos os níveis de ensino para a avaliação dos alunos, no 
que diz respeito à Matemática.

Além disso, há uma diferença entre a magnitude dos números utilizados em cada atividade - as operações sempre envolvem números de maior magnitude. Nos problemas, mesmo ao longo da escolaridade, mantêm-se quantidades de menor magnitude (até unidade de milhar).

Vale ressaltar aqui: sempre que há uma relação entre aquilo que é explorado em outras atividades e o que é mobilizado na resolução de problemas, o registro das atividades antecede a sua mobilização nos problemas. Um indício de que nos problemas são utilizados conceitos já aprendidos anteriormente. No entanto, em todos os cadernos, a maioria dos problemas não apresenta relação com outras atividades e, além disso, nota-se que muitos deles repetem um mesmo formato, uma mesma proposta, um mesmo "tipo", variando a temática e os dados. Assim, parece que a sua utilização tem o objetivo de ensinar os alunos a resolverem os "problemas-tipo" (SARRAZY, 2003), que são do mesmo "tipo" daqueles observados nos cadernos de deveres mensais.

Em relação aos conteúdos envolvidos nos problemas, no período até 1914 há uma centralidade no uso de "problemas-tipo" contendo a ideia de proporcionalidade. Já nos cadernos utilizados a partir de 1915 há uma centralidade de um determinado conteúdo em um certo período de tempo, isto é, durante um período específico, há a proposição de vários problemas de um "mesmo tipo". Por exemplo, no caderno de Marcelo, nos meses de dezembro de 1922 e janeiro de 1923, a maioria dos problemas envolvia o cálculo de volumes. O mesmo se observa nos outros cadernos do aluno: problemas envolvendo determinado conceito, como juros, cálculo de superfície, transformação de unidades de medida, frações, são propostos em grande número em um intervalo de tempo, ganhando centralidade.

A centralidade de um conteúdo em dado período permite identificar uma sequência no ensino de conteúdos a partir dos problemas propostos. Nos cadernos da aluna Juliana, do CE e do CM, por exemplo, apresenta-se a seguinte sequência: adição e subtração; essas duas operações combinadas com a multiplicação; as três operações anteriores combinadas com a divisão; perímetro do quadrado e do retângulo; lucro, envolvendo cálculo do preço de compra, de venda ou do lucro obtido; perímetro do triângulo; superfície do quadrado e do retângulo; volume do cubo.

A possibilidade de analisar conjuntos de cadernos de alguns alunos, utilizados ao longo de diferentes anos e de diferentes níveis de escolaridade, permitiu a observação de que a relação dos problemas com uma sequência de ensino de conteúdos não é apenas uma opção individual de um professor, de uma escola ou de um nível escolar. 
Ainda sobre a marcha de ensino, em alguns cadernos utilizados a partir de 1915, como os de Marcelo e de Alan, há um "número" de identificação do problema e, por vezes, ele está acompanhado com a indicação de uma página.

O fato de a numeração dos problemas, apesar de não ser ininterrupta, estar em ordem crescente no decorrer do caderno parece indicar que o professor utilizava a sequência proposta pelo livro didático para determinar a marcha do ensino que, devido à centralidade dos problemas nesses cadernos, era determinada pelas opções na proposição de problemas.

Apesar da centralidade de alguns conteúdos a cada período de tempo, problemas que envolvem as relações entre múltiplos e submúltiplo das unidades de medida, a ideia de proporcionalidade, de lucro e da fração de uma quantidade, aparecem, por vezes, ao longo do tempo, permeando aqueles relacionados ao conteúdo central de cada período. Tais assuntos são, até mesmo, utilizados em um mesmo problema, juntamente com o conteúdo tratado naquele momento.

Ainda que essas ideias estivessem presentes em problemas durante praticamente toda a escolaridade dos alunos nos diferentes cadernos analisados, não se pode dizer que elas se apresentassem, ao longo do tempo, sempre da mesma forma. Algumas mudanças puderam ser observadas, no que diz respeito à solução proposta, ao tipo de problema relacionado aos dados fornecidos e à questão colocada.

Algumas mudanças são observadas ao longo dos níveis de escolaridade, por exemplo, nos cadernos de Marcelo e de Juliana, em relação aos problemas envolvendo a ideia de proporcionalidade.

Nos cadernos de Marcelo, tais problemas, a partir do CM, recebem forma de solução diferente daquela apresentada no caderno do CE, que passa a ser utilizada em todos os problemas que envolvem tal ideia. No CE, a solução inclui uma divisão que permite encontrar o valor de um elemento e, após uma multiplicação que leva ao valor da quantidade solicitada, as duas operações são registradas de forma separada (Figura 2). No caderno do CM, a ideia de encontrar o valor unitário permanece, mas, a partir desse momento, o registro das relações adota outro formato, na forma fracionária, que permite simplificações para além da multiplicação e da divisão (Figura 3). 


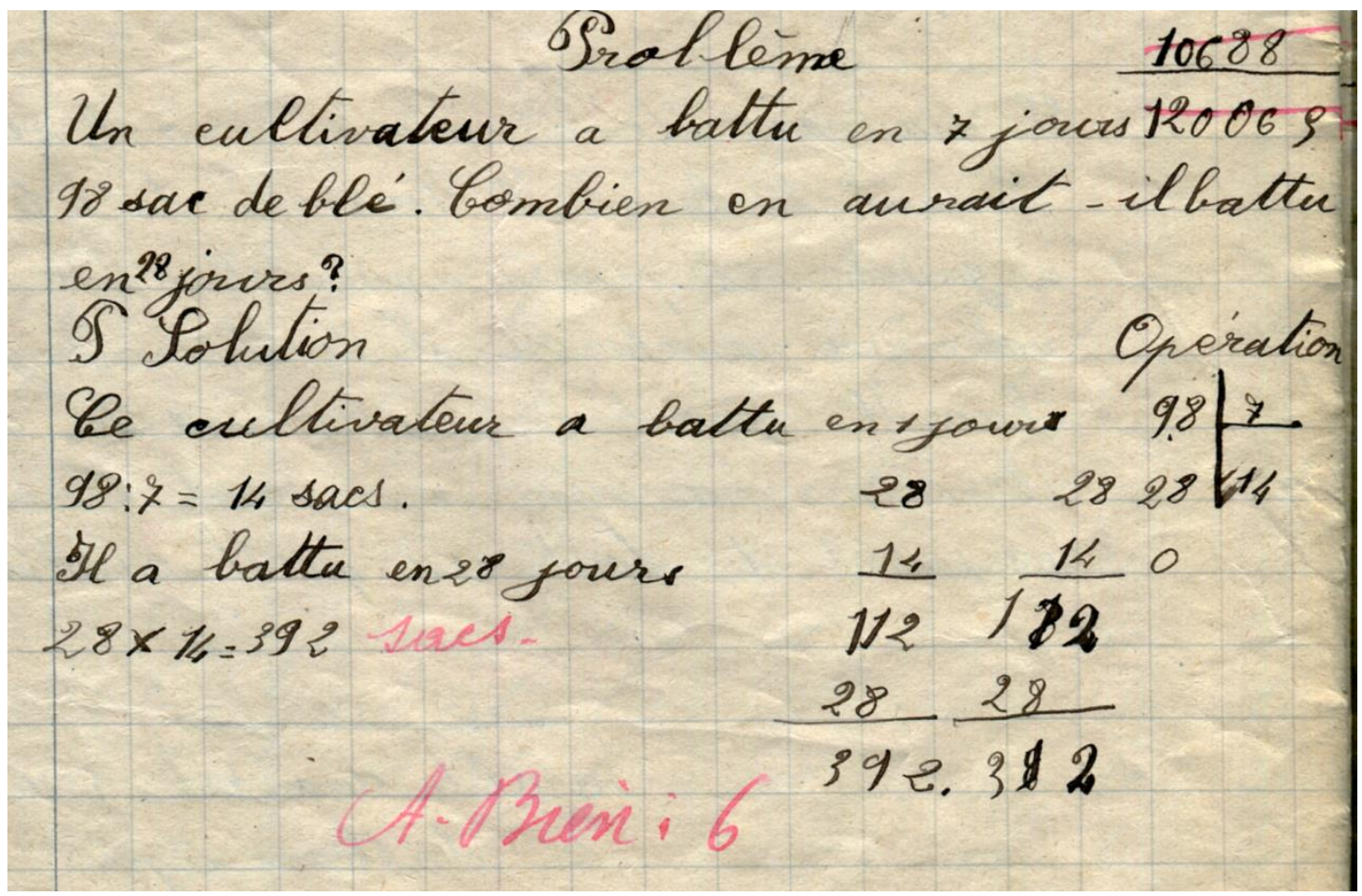

Figura 4 - Problema resolvido por Marcelo no CE

Fonte: Coleção de cadernos do Fonds Histoire de l'Education, da Universidade de Limoges (2017).

Problema
Um agricultor produziu em 7 dias
98 sacos de trigo. Quanto ele produzirá
em 28 dias?
Solução
Esse agricultor produziu em 1 dia
$98: 7=14$ sacos
Ele produziu em 28 dias
$28 \times 14=392$ sacos.

Quadro 2 - Tradução do problema da Figura 2

Fonte: Tradução livre feita pela autora (2017).

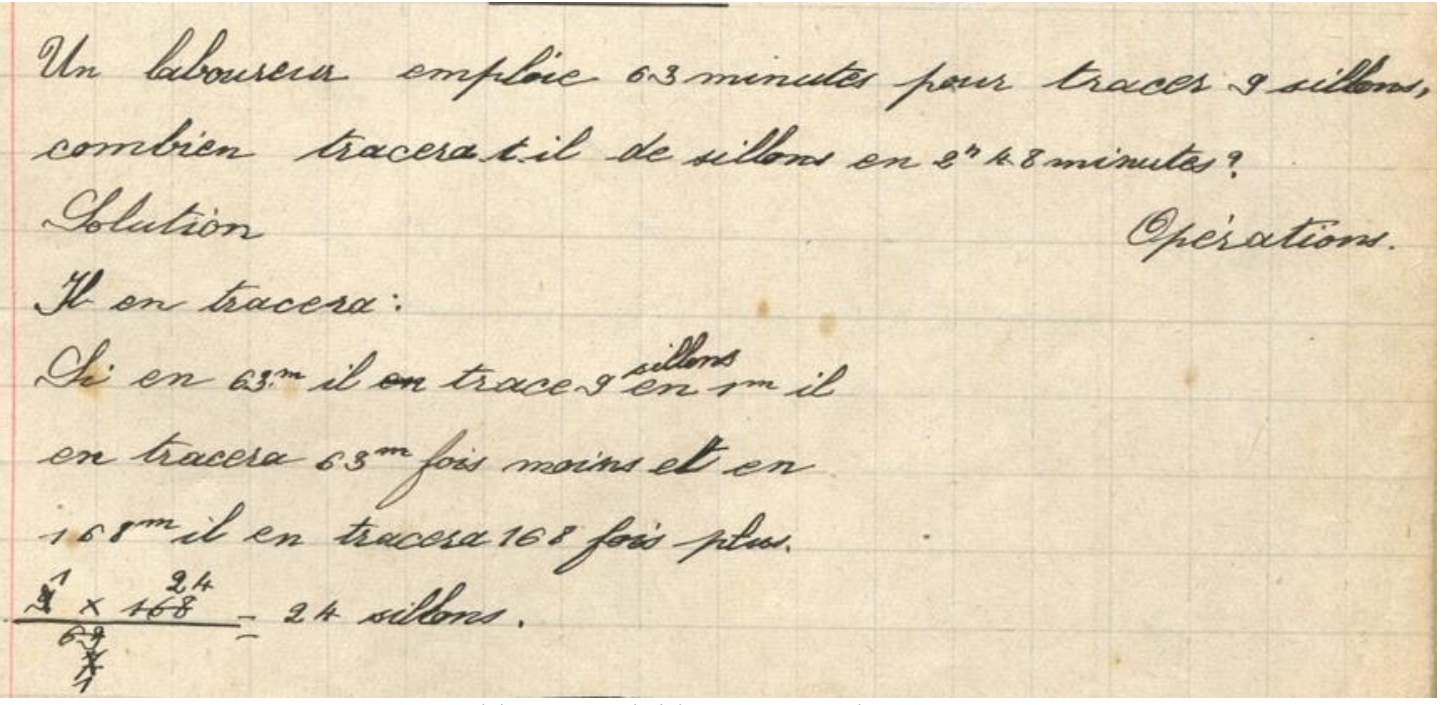

Figura 5- Problema resolvido por Marcelo no CM

Fonte: Coleção de cadernos do Fonds Histoire de l'Education da Universidade de Limoges (2017). 


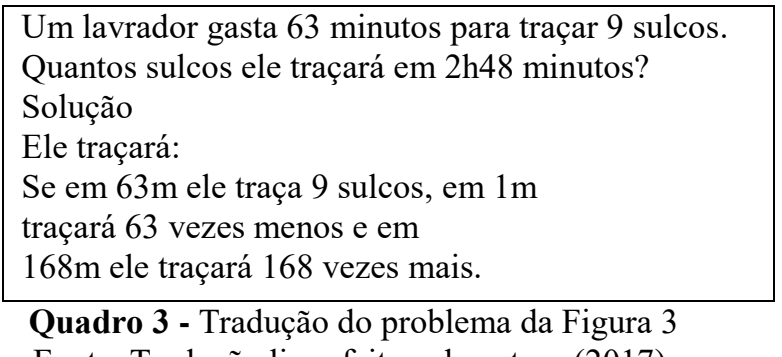

Fonte: Tradução livre feita pela autora (2017).

Uma característica identificada em todos os cadernos é a de que, ao longo do tempo, os tipos de problemas que permanecem apresentam um aumento do número de relações envolvidas no enunciado, o que tem como consequência a utilização de um maior número de procedimentos e operações na solução.

Ainda em relação aos conteúdos dos problemas, nota-se que alguns deles se relacionam diretamente ao tipo de problema apresentado, como regra de três, superfície. No entanto, outros, como frações e sistema de medidas, acabam sendo utilizados em problemas de tipos já trabalhados anteriormente, apenas alterando o número apresentado, ora na forma decimal, ora na forma fracionária.

No período dos cadernos analisados, estiveram em voga dois programas de ensino, um do ano de 1882 e outro proposto no ano de 1923. Ambos foram considerados por estabelecerem relações entre os conteúdos propostos pela documentação oficial e os conteúdos abordados nos problemas. Por não estarem disponíveis os cadernos de todo o período escolar, sem interrupções, não foram possíveis conclusões relativas a conteúdos propostos nos programas e não utilizados nos cadernos. No entanto, puderam ser analisados conteúdos abordados nos cadernos, mas não indicados nos programas.

Nos cadernos do CE de Juliana, no ano letivo de 1933-1934, por exemplo, há conteúdos como cálculo do perímetro, da superfície, do volume e a ideia de proporcionalidade, que não são listados nem no programa de 1882, nem no programa de 1923. Ainda, nos cadernos de Marcelo, do CM, do ano letivo de 1921-1922, são utilizados problemas que envolvem o cálculo de densidade, conteúdo listado no programa do CS de 1923 (posterior ao que estava em vigor no momento de uso do caderno). O que se nota é que os conteúdos presentes nos cadernos não correspondem exatamente à listagem de conteúdos dos programas, embora, muitas vezes, a relação esteja estabelecida.

A marcha de ensino, para além da identificação de conteúdos ensinados e sua ordenação na sequência de proposição dos problemas, envolve também as orientações dos professores para sua resolução. Algumas delas se revelam nas regras utilizadas para a resolução, que podem ser observadas na organização espacial dos problemas, ou na forma de 
escrita da solução. Tais aspectos são identificados nesta pesquisa como "regras", uma vez que são utilizados pelos mesmos alunos em diferentes anos escolares, por diferentes estudantes de diferentes escolas e em diferentes períodos temporais.

A observação dessas orientações para o ensino ganha alguns outros elementos nos cadernos de Juliana, do CM. A partir de maio de 1936, a questão do problema passa a ser grifada a lápis. Esse pode ser um indício das orientações do professor no processo de resolução de um problema: a importância de localizar a questão que é colocada.

Outro indício de orientação desse mesmo professor na resolução de problemas que incluem o cálculo do perímetro é a indicação, por escrito, para que os alunos façam um croqui. Nos cadernos analisados, a representação pictórica ocorre em alguns problemas que evolvem cálculo de perímetro e área. No entanto, a utilização de croquis envolve mais do que a representação pictórica, pois implica também a proporcionalidade entre a medida real e a representação.

As observações anteriores não pretendem afirmar que estas e outras orientações não fossem realizadas por outros professores. O objetivo é destacar a opção deste professor de fazer orientações que, de alguma forma, ganhavam forma de registros nos cadernos. Por que o registro de tais orientações? Seria uma forma de mostrar a sua importância no processo de solução dos problemas?

\section{As temáticas dos problemas: que relação com a vida?}

As pesquisas já realizadas por D’Enfert (2006, 2015) e por Sarrazy (2003) sobre a exploração das legislações francesas desse período histórico identificam que uma das orientações aconselha levar em consideração, no ensino de Matemática, situações da vida cotidiana. Mas como essa relação com a vida, com a prática profissional está presente nos problemas propostos e registrados nos cadernos escolares?

Quando se olha para as temáticas dos problemas ao longo do tempo, é possível observar algumas alterações naquelas que são privilegiadas em cada momento. Nos cadernos utilizados até a década de 1920, situações da vida no campo têm grande representatividade na temática dos problemas. No entanto, raramente aparecem nos cadernos aqueles relacionados à moral, com referência ao consumo de cigarro e gastos em um cabaré, como "consumo inútil".

Nos cadernos utilizados na década de 1930, a temática relativa à vida no campo permanece. No entanto, ganham maior espaço situações da vida em família, algumas relacionadas à escola e, principalmente, ao comércio, não necessariamente relacionadas à vida 
no campo. Tomam conta dos cadernos compras e vendas realizadas por comerciantes ou por uma família - artigos para a casa, livros, camisas, etc. -, bem como alguns problemas, como a distância percorrida para ir à escola. Ao mesmo tempo, passam a ser utilizados, em maior número, problemas com "eu”: quem realiza as ações não é o fazendeiro, o açougueiro ou o comerciante, mas sou "eu". Esta opção parece indicar uma forma de estreitar ainda mais a relação das crianças com os problemas.

Nos cadernos, a referência à futura prática profissional, como identificada por D’Enfert (2015) na legislação oficial, também é observada, mas nem sempre da mesma forma. Em um período inicial, essa menção está ligada ao trabalho no campo; e, com o tempo, ganha espaço o trabalho no comércio, com compra e venda de produtos não necessariamente vinculados ao trabalho do campo. Para além da relação com a vida de trabalho, muitos são os problemas que remetem também à vida em família, privilegiando aqueles que envolvem a ideia de economia doméstica.

Ao discutir as temáticas dos problemas nos manuais escolares, Sarrazy (2003) observa que, a partir do programa de 1923, há algumas pequenas alterações nas propostas dos livros, dentre elas a abordagem de problemas relativos a situações de esporte ou de descobertas do momento. No entanto, esse tipo de temática não foi identificada nos cadernos analisados. Comprar, vender, calcular preços de produtos são as ações - muitas vezes combinadas com as medidas - implicadas na quase totalidade dos problemas.

Apesar de as temáticas sofrerem alterações ao longo do tempo, o "tipo de problema" parece permanecer o mesmo: mudam os personagens, mudam os artigos comprados ou vendidos; no entanto, a estrutura do texto do problema e também a estrutura da solução permanecem muito semelhantes, pelo menos naquilo que diz respeito ao registro encontrado nos cadernos.

Em todo o período, a presença da mulher continua relacionada às tarefas de casa e à ideia de generosidade.

\section{Relações entre os problemas nos diferentes tipos de cadernos}

A existência de conjuntos de cadernos de um mesmo aluno, com cadernos de deveres mensais e diários utilizados em um mesmo período, permitiu estabelecer relações entre os problemas propostos nas atividades diárias e aqueles selecionados para compor as avaliações mensais.

Apresenta-se como exemplo a relação observada nos cadernos da aluna Juliana, 
destacando-se que relações semelhantes são observadas nos demais conjuntos de cadernos. Foi possível estabelecer relações entre os problemas utilizados nas aulas de Aritmética e aqueles apresentados como forma de avaliação, uma vez que os cadernos de deveres diários do CE têm registros contínuos entre novembro de 1933 e julho de 1934, e o caderno de deveres mensais possui registros nesse mesmo período.

Os problemas utilizados nas avaliações são do mesmo tipo daqueles trabalhados nas aulas, envolvem o mesmo conteúdo, são resolvidos com o mesmo tipo de solução e, na maioria das vezes, têm uma mesma temática. No exemplo que segue, o problema apresentado na avaliação (Figura 4) traz o mesmo texto apresentado anteriormente no caderno de deveres diários (Figura 5), com alteração apenas nos números apontados no problema.

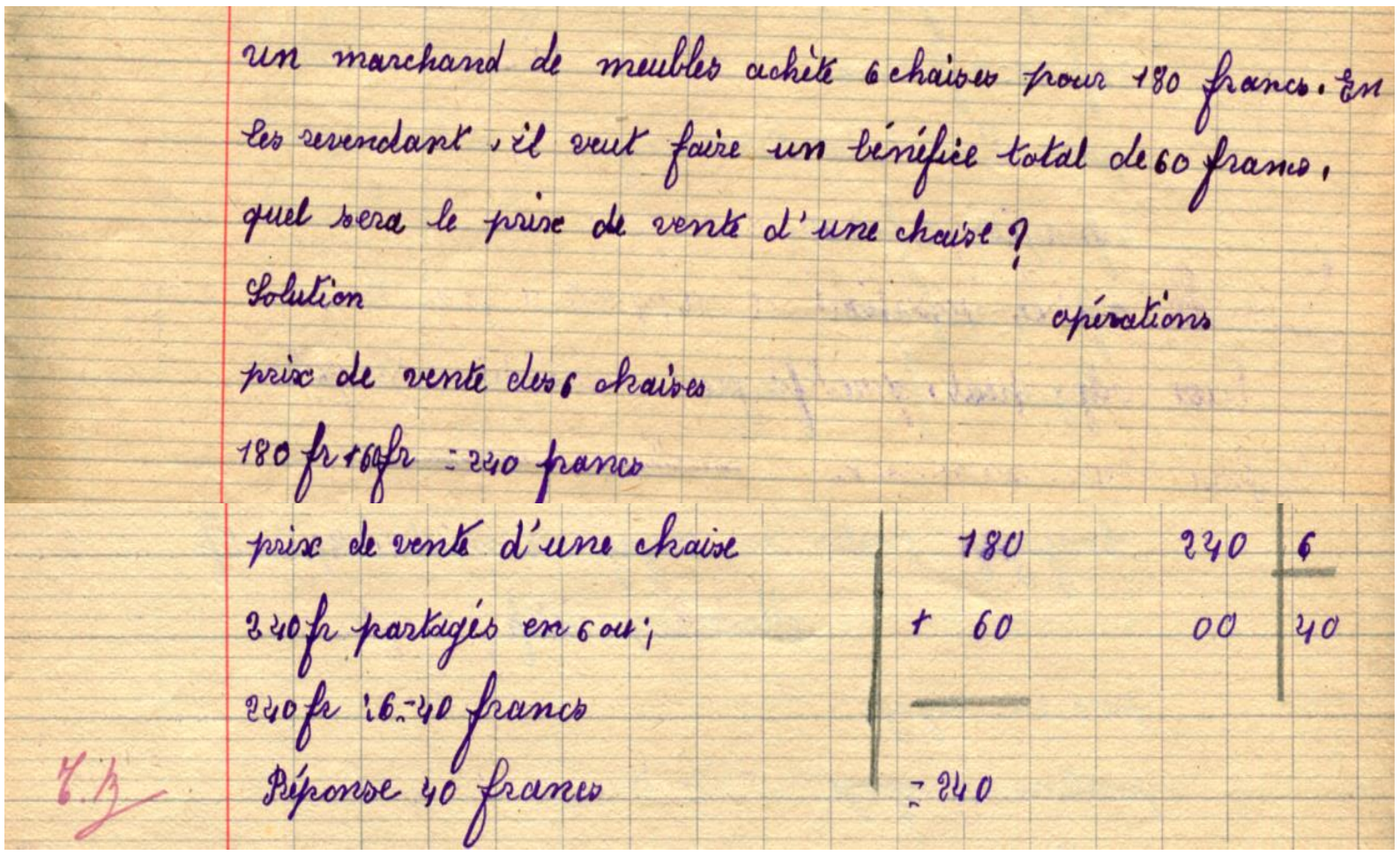

Figura 6 - Problema resolvido por Juliana em 20 de fevereiro de 1934

Fonte: Coleção de cadernos do Fonds Histoire de l'Education, da Universidade de Limoges (2017).

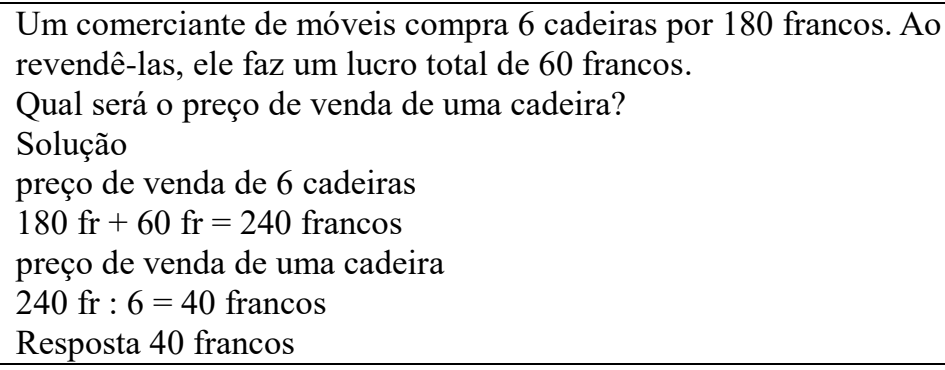

Quadro 4 - Tradução do problema da Figura 4

Fonte: Tradução livre feita pela autora (2017). 


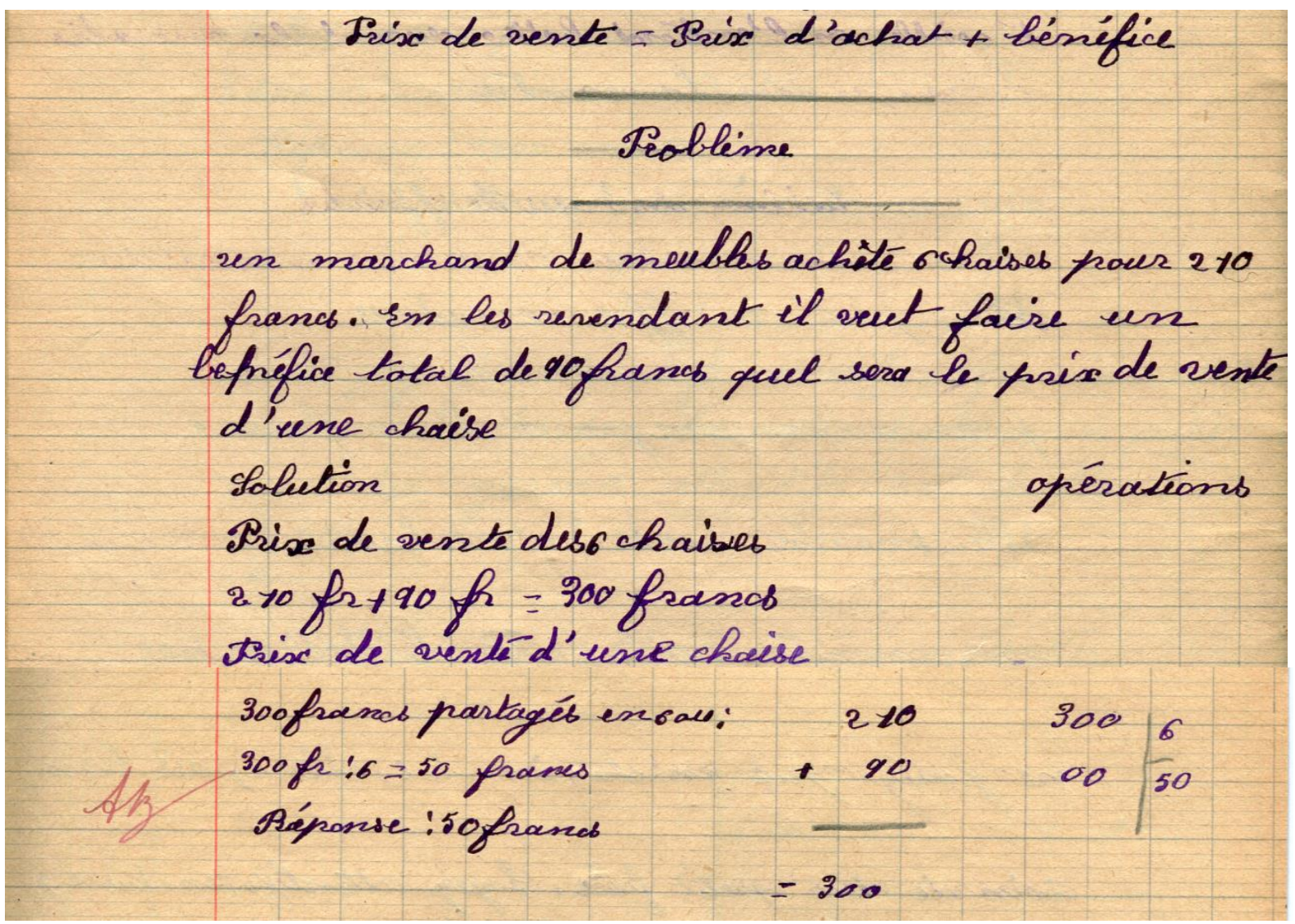

Figura 7 - Problema resolvido por Juliana em 31 de janeiro de $1934^{11}$

Fonte: Coleção de cadernos do Fonds Histoire de l'Education, da Universidade de Limoges (2017).

No conjunto de cadernos do aluno Alan, por exemplo, não há cadernos de deveres mensais; no entanto, há dois tipos de cadernos utilizados ao mesmo tempo, que parecem ser: um para a sala de aula e outro para atividades realizadas em casa. Também, nesses dois tipos de cadernos de um mesmo período, há grande semelhança entre os tipos de problemas utilizados, que abordam as mesmas temáticas e os mesmos conceitos, sendo, por vezes, muito semelhantes, com alteração apenas dos valores.

A utilização de "problemas-tipo", já identificada por Sarrazy (2003), ao analisar legislações e manuais, é também observada nos cadernos. Nos cadernos de deveres diários, há a repetição de "problemas-tipo" e, nas avaliações, parece que o objetivo é verificar se os alunos aprenderam a resolver estes "tipos" de problemas, reproduzindo o mesmo "tipo" de solução, as "soluções-tipo".

\section{Considerações}

\footnotetext{
${ }^{11}$ A tradução seria a mesma apresentada no Quadro 5, alterando-se apenas os valores.
} 
As características observadas na análise dos cadernos indicam, no que diz respeito ao uso de problemas no ensino, algumas alterações ao longo do tempo, como: i) um movimento em relação às temáticas envolvidas nos problemas: aos poucos diminui a presença de aspectos da vida no campo, e ii) uma alteração na marcha do ensino, que no período entre 1915 e 1936 passa a envolver a centralidade de determinado conteúdo - relacionado a problemas-tipo - em um determinado período (um ou dois meses), gerando a proposição de uma sequência de conteúdos ao longo do tempo.

No entanto, nos cadernos, assim como observou Sarrazy (2003) na análise de manuais deste mesmo período histórico, não há alterações significativas no esquema didático que privilegiava e continua a privilegiar o ensino de "soluções-tipo" - a partir da memorização e reprodução - para "problemas-tipo".

Uma das características principais apontadas por D’Enfert (2015), ao caracterizar o período entre 1915 e 1936, buscando diferenciá-lo do período anterior, seria um ensino pela ação, em lugar de um ensino pela observação, privilegiado no período anterior (1890-1914). Esse movimento não é identificado nos registros dos cadernos escolares, no que diz respeito aos problemas e, possivelmente, tampouco no que diz respeito ao ensino de Aritmética, uma vez que ali os problemas eram centrais. A observação anterior de que o ensino de problemas privilegia o ensino de "soluções-tipo" a serem memorizadas e reproduzidas não remete nem a um ensino pela observação, nem a um ensino pela ação.

Os trabalhos de D’Enfert $(2006,2015)$ e de Sarrazy (2003), como já abordado neste texto, tiveram, respectivamente, como principais documentos de estudo as legislações e os manuais. Foi interesse deste estudo direcionar o olhar para o modo como se deu o consumo dessas determinações e orientações. Por isso foi fundamental o diálogo com os resultados de tais pesquisas.

No registro dos cadernos, nota-se o consumo daquilo que estava proposto, tanto nos programas como nos manuais, por exemplo, na utilização de muitos dos conteúdos listados nos programas para a proposição dos problemas e também no registro de "números" e páginas relacionadas a eles, o que revela o uso dos problemas propostos nos manuais. No entanto, na perspectiva apresentada por Certeau (2014), o consumo se dá de forma criadora e produtora, com movimentos de pluralidade, de criatividade e de produção nesse processo. Tais movimentos são identificados, por exemplo, quando, nos cadernos, problemas envolvem conteúdos não listados nos programas ou, então, listados nos programas do nível seguinte de escolaridade ou assumem centralidade, tornando-se, em alguns momentos, a única atividade relacionada ao ensino de Aritmética. 
$\mathrm{Na}$ análise realizada, de forma geral, os problemas parecem estar presentes nos cadernos escolares como um saber a ser ensinado, e não apenas como uma atividade complementar no ensino de outros saberes. Novaes, Bertini e Siqueira Filho (2017) discutem a possibilidade de utilização dos cadernos de alunos em pesquisas que têm como foco os saberes matemáticos no ensino primário e identificam a possibilidade de, por meio das tarefas escolares $^{12}$, acessar a Matemática ensinada ${ }^{13}$, entendida como aquela produzida em processos de interação e encerrada nos cadernos escolares.

Analisando as tarefas destinadas ao ensino de Aritmética, a relação entre elas e as determinações e orientações para o ensino, consideram-se os problemas como um saber a ser ensinado a partir de indícios tais como: a centralidade dos problemas tanto nos cadernos de deveres diários como nos cadernos de deveres mensais; a relação entre os problemas e as demais atividades de ensino de Aritmética nos cadernos; e, principalmente, a existência de "problemas-tipo" com "soluções-tipo" que são ensinadas e, em momento posterior, são objeto de avaliação e, na maioria das vezes, o único objeto de avaliação.

Assim, foi possível identificar o problema de aritmética como um saber a ser ensinado a partir das relações estabelecidas com ele. Como afirma Charlot (2000, p. 62), "o saber não existe senão sob formas específicas [...] de relação com o mundo". Para este autor, não é o saber em si que assume uma forma, mas sim a relação que se estabelece com ele. Portanto, considera-se que os problemas de Aritmética assumem a forma de um saber a ser ensinado, pela análise que se faz das tarefas escolares, resultantes da relação entre os professores e os saberes matemáticos, bem como da sua relação com os alunos.

\section{Referências}

BERTINI, L. F. O Manual do Ensino Primário, de Miguel Milano: que problemas? Revista de História da Educação Matemática, Sociedade Brasileira de História da Matemática, Rio Claro, v. 2, p. $117-129,2016$.

BURIGO, E. Z.; SANTOS, J. G. Os problemas de aritmética na Revista do Ensino dos anos 1950. In: SEMINÁRIO TEMÁTICO - SABERES ELEMENTARES MATEMÁTICOS DO ENSINO PRIMÁRIO (1890-1971): O QUE DIZEM AS REVISTAS PEDAGÓGICAS?, 12., 2015, Pontifícia Universidade Católica do Paraná. Anais... Curitiba: PUCPR, 2015. p. 13 - 22. Disponível em: $<$ http://www2.td.utfpr.edu.br/seminario_tematico/ANAIS/1_BURIGO_SANTOS.pdf $>$. Acesso em: 10 jan. 2016.

\footnotetext{
12 De acordo com Gvirtz e Larrondo (2008, p. 35), “o caderno escolar - um espaço de interação entre professores e alunos - permite que sejam vistos os efeitos dessa interação, ou seja, a tarefa escolar".

${ }^{13}$ Os autores tomam como referência a afirmação de Charlot (2000) de que é possível se falar de um saber encerrado nos livros, que são produzidos em processo de relação e que, em momento posterior, aparecem como objeto autônomo.
} 
CERTEAU, M. A invenção do cotidiano: artes de fazer. Tradução de Ephraim Ferreira Alves. 22. ed. Petrópolis, RJ: Vozes, 2014.

CHARLOT, B. Da relação com o saber: elementos para uma teoria. Porto Alegre: Artmed, 2000.

D'ENFERT, R. L'enseignement mathématique à l'école primaire de la Révolution à nos jours: Textes officiels - Tome 1: 1791-1914. PULIM - Press Universitaires de Limoges, 2003.

D'ENFERT, R. L'enseignement mathématique à l'école primaire de la Troisième République aux années 1960: enjeux sociaux et culturels d'une scolatisation « de masse ». SMF - Gazette, n. 108, abr. 2006. p. 68-81. Disponível em:

$<$ http://smf4.emath.fr/Publications/Gazette/2006/108/smf_gazette_108_67-81.pdf>. Acesso em: 16 fev. 2017.

D'ENFERT, R. L'enseignement mathématique à l'école primaire de la Révolution à nos jours: Textes officiels - Tome 2: 1915-2000. PULIM - Press Universitaires de Limoges, 2015.

GVIRTZ, S; LARRONDO, M. Os cadernos de classe como fonte primária de pesquisa: alcances e limites teóricos e metodológicos para sua abordagem. In: MIGNOT, A. C. V. (Org.). Cadernos à vista: escola, memória e cultura escrita. Rio de Janeiro: EdUERJ, 2008. p. 35 - 48.

HÉBRARD, J. Por uma bibliografia material das escritas ordinárias: o espaço gráfico do caderno escolar (França - séculos XIX e XX). Tradução de Laura Hansen. Revista Brasileira de História da Educação, Universidade Estadual de Maringá, n. 1, p. 115 - 141, jan./jun. 2001.

NOVAES, B. W. D.; BERTINI, L. F.; SIQUEIRA FILHO, M. G. Cadernos de alunos com registros de aula de matemática: textos e contextos. In: RIOS, et al. Cadernos escolares e a escrita da história da educação matemática. São Paulo: Livraria da Física, 2017.

SARRAZY, B. Le problème d'arithmétique dans l'enseignement des mathématique à l'école primaire de 1887 à 1990. Carrefours de L'Éducation, Université de Picardie, França, n. 15, p. 82 - 101, jan./jun. 2003. Disponível em: <https://www.cairn.info/revue-carrefours-de-1-education-2003-1-page82.htm>. Acesso em: 24 fev. 2017.

SOUZA, A. F. Discursos para ensinar problemas aritméticos (São Paulo, 1890-1930). 2017. 135f. Dissertação (Mestrado em Ciências) - Escola de Filosofia Letras e Ciências Humanas, Universidade Federal de São Paulo, São Paulo, 2017.

SOUZA, A. F.; BERTINI, L. F. Como ensinar problemas? Os saberes nos artigos da Revista de Ensino (São Paulo, 1902-1919). Caminhos da Educação Matemática em Revista (On-line), Instituto Federal de Sergipe, v. 6, p. 27 - 44, 2016.

VIÑAO, A. Os cadernos escolares como fonte histórica: aspectos metodológicos e historiográficos. In: MIGNOT, A. C. V. (Org.). Cadernos à vista: escola, memória e cultura escrita. Rio de Janeiro: EdUERJ, 2008. p. 15 - 33.

VIRGENS, W. P.; LEME DA SILVA, M. C. Propostas escolanovistas para a resolução de problemas de aritmética nas revistas pedagógicas. In: SEMINÁRIO TEMÁTICO - A CONSTITUIÇÃO DOS SABERES ELEMENTARES MATEMÁTICOS: A ARITMÉTICA, A GEOMETRIA E O DESENHO NO CURSO PRIMÁRIO EM PERSPECTIVA HISTÓRICO-COMPARATIVA, 1890-1970, 11., 2014, Florianópolis. Anais... Universidade Federal de Santa Catarina, Florianópolis, 2014. p. 1 - 17. Disponível em: <http://seminariotematico.ufsc.br/files/2014/03/ATA5_Virgens_Leme-daSilva_art_DAC.pdf $>$. Acesso em: 10 jan. 2016. 
Submetido em 26 de Maio de 2018. Aprovado em 24 de Outubro de 2019. 